\title{
Solanine Interferes with AKT/p-AKT and PI3K/p-PI3K Pathway to Inhibit HIF and Destroy Cell Energy Metabolism
}

\author{
Yidong Wang*, Peng Wang, Wenbing Zhao \\ Department of Urology Surgery, Shanxi Hospital of Integrated Traditional and Western Medicine, Taiyuan, China \\ Email: *wyd163com@163.com, wang_1_peng@126.com
}

How to cite this paper: Wang, Y.D., Wang, P. and Zhao, W.B. (2021) Solanine Interferes with $\mathrm{AKT} / \mathrm{p}-\mathrm{AKT}$ and $\mathrm{PI} 3 \mathrm{~K} / \mathrm{p}$ PI3K Pathway to Inhibit HIF and Destroy Cell Energy Metabolism. Journal of Biosciences and Medicines, 9, 89-95.

https://doi.org/10.4236/jbm.2021.910008

Received: August 16, 2021

Accepted: October 17, 2021

Published: October 20, 2021

Copyright ( 2021 by author(s) and Scientific Research Publishing Inc. This work is licensed under the Creative Commons Attribution International License (CC BY 4.0).

http://creativecommons.org/licenses/by/4.0/

\begin{abstract}
The purpose of this study was to explore the mechanism of Solanine disrupting energy metabolism in human renal cancer ACHN cells and to clarify its target. The specific method was to culture human renal cancer ACHN cell lines, and to intervene with Solanine of high, medium and low concentrations. The content of ATP in cells was measured by ELISA method. The expression of HIF- $1 a$ protein and the expression of PI3K, AKT, p-PI3K, p-AKT in PI3K/AKT pathway were detected by Western blotting. The results showed that compared with the control group, the relative expression of $\mathrm{p}-\mathrm{PI} 3 \mathrm{~K}$ and p-AKT showed a downward trend with the increase of Solanine concentration $(\mathrm{P}<0.05)$, while the relative expression of PI3K and AKT showed no significant change $(\mathrm{P}>0.05)$. In addition, the relative expression of HIF-1 $\alpha$ also showed a downward trend $(\mathrm{P}<0.05)$. According to the above results, it is suggested that Solanine can significantly inhibit the energy metabolism of renal cancer cells, the main mechanism of which is the down-regulation of HI- 1 af downstream of the PI3K/Akt pathway by inhibiting the phosphorylation process of $\mathrm{PI} 3 \mathrm{~K} / \mathrm{p}-\mathrm{PI} 3 \mathrm{~K}$ and Akt/p-Akt.
\end{abstract}

\section{Keywords}

Renal Carcinoma, Solanine, Energy Metabolism, PI3K/Akt Signaling

Pathway, HIF-1 Alpha

\section{Introduction}

Renal cell carcinoma is a common urinary malignancy, second only to bladder cancer, accounting for about $2 \%-3 \%$ of adult malignancies [1]. Renal cancer is not sensitive to radiotherapy and chemotherapy, and surgery is the first choice for its treatment. However, about $20 \%$ of patients still develop metastasis after 
radical nephrectomy with poor recovery, and the five-year survival rate is less than $10 \%$ [2]. Therefore, how to improve the prognosis of patients with renal cancer and prolong their survival time has become an urgent problem to be solved clinically.

PI3K/Akt signaling pathway plays a key role in energy metabolism of tumor cells. Activation of PI3K/Akt signaling pathway has been found in a variety of tumors, and activated Akt (p-Akt) can phosphorylate a variety of downstream substrates related to cell survival and interfere with energy metabolism of tumor cells [3]. Previous studies have confirmed that PI3K/Akt signaling pathway plays an important role in the occurrence, progression and metastasis of renal cell carcinoma, and the activation degree of this signaling pathway is closely related to the survival time of patients with renal cell carcinoma [4].

Solanine is an alkaloid extracted and isolated mainly from the whole grass or immature fruits of Solanine, a plant of the Solanaceae family. Studies have shown that Solanine can not only change the tumor cell cycle and inhibit its growth, but also act on multiple targets of the endogenous and exogenous apoptosis pathway of tumor cells and cause the apoptosis of tumor cells [5] [6]. Through previous studies, it has been confirmed that Solanine can significantly reduce the ATP content of ACHN renal cancer cells, suggesting that glycolysis may be one of its targets [7] [8] [9]. However, the specific mechanism of action of Solanine in inhibiting glycolysis of tumor cells remains unclear. The answer to this scientific question will help to further reveal the relationship between changes in tumor energy metabolism and tumor progression, and provide a new therapeutic strategy for targeting tumor-specific glycolysis.

\section{Materials and Methods}

\subsection{Main Reagents}

Human renal cancer cell line ACHN was preserved in the central laboratory of Shanxi Integrated Traditional Chinese and Western Medicine Hospital. DMEM medium and calf serum were purchased from Hyclone Company, USA. Solanine is purchased from Chengdu Munster Biotechnology Co., Ltd. (purity $\geq 99 \%$ ); ATP content test box was purchased from Nanjing Jiancheng Institute of Biological Engineering; HIF-1 $\alpha$, PI3K, Akt, p-Akt, p-PI3K antibodies are Cell Signaling Company products.

\subsection{Cell Culture}

ACHN cell lines were cultured in DMEM medium containing 10\% calf serum, supplemented with appropriate amount of antibiotics (100 units/mL penicillin and $100 \mu \mathrm{g} / \mathrm{mL}$ strepomycin), and incubated in a mixture incubator at $37^{\circ} \mathrm{C}$ and $5 \% \mathrm{CO}_{2}$. The time of cell change was 2 - 3 days, and the passage was $3-5$ days.

\subsection{ATP Content Determination}

ACHN cells in logarithmic growth phase were digested with $0.25 \%$ trypsin and 
added into DMEM medium containing $10 \%$ calf serum to prepare single cell suspension with cell density of $5 \times 10^{4}$. The cells were inoculated on 96-well plate with $100 \mu \mathrm{L}$ per well. After inoculation with medium, the cells were pre-cultured in an incubator containing $5 \% \mathrm{CO}_{2}$ at $37^{\circ} \mathrm{C}$ for $24 \mathrm{~h}$. Add $20 \mu \mathrm{L}$ Solanine of different concentrations $(0.5,2,8 \mu \mathrm{g} / \mathrm{mL})$ to each well, and set the control group without drug, set 6 duplicate Wells in parallel to each group. After $48 \mathrm{~h}$ of drug administration, discard the supernatant by centrifugation, make cell suspension with normal saline, then add double steamed water, and continue to heat for $10 \mathrm{~min}$ after homogenate is broken in boiling water bath. Centrifugal supernatant was taken for determination. See ATP Kit Instructions for detailed procedures.

\subsection{The Expression of HIF-1 $\alpha$, PI3K, Akt, p-PI3K, p-Akt and Other Proteins Were Detected by Western Blot}

ACHN cells were inoculated into culture flask at a density of $1 \times 10^{6}$ per flask, and the four groups were recorded as control group, low-dose Solanine group $(0.5 \mu \mathrm{g} / \mathrm{mL})$, medium-dose Solanine group $(2 \mu \mathrm{g} / \mathrm{mL})$, and high-dose Solanine group $(8 \mu \mathrm{g} / \mathrm{mL})$. After the cells adhered to the wall, the supernatant was discarded, and the cells were respectively added and incubated for $24 \mathrm{~h}$. After that, all cells were collected and washed twice with PBS at $4^{\circ} \mathrm{C}$. The pre-cooled cell lysis buffer was added, and the lysates were lysed on ice for $15 \mathrm{~min}$. The lysates were centrifuged at $10,000 \times \mathrm{g}$ at $4^{\circ} \mathrm{C}$ for $30 \mathrm{~min}$. The protein concentration of supernatant was measured by Bradford method. Proteins were separated by $15 \%$ SDS-polyacrylamide gel electrophoresis. After electrophoresis, the protein was transferred to nitocellulose membrane, which was sealed with $5 \%$ skim milk powder solution at $37^{\circ} \mathrm{C}$ for $2 \mathrm{~h}$, then reacted with HIF- $1 \alpha$, PI3K, Akt, p-PI3K, p-Akt and other primary antibodies at $37^{\circ} \mathrm{C}$ for $2 \mathrm{~h}$, respectively. PBST was washed twice for $15 \mathrm{~min}$ each, and then reacted with horseradish labeled second antibody at $37^{\circ} \mathrm{C}$ for $1 \mathrm{~h}$. After fully washing with PBST, DAB was used for color rendering, scanning records were recorded, and anti-actin antibody was applied to determine the consistency of loading volume.

\subsection{Statistical Processing}

Data were expressed as mean \pm standard deviation $(\bar{x} \pm s)$, and SPSS 21.0 statistical software was used for data analysis. Analysis of variance was used for comparison of means between 2 groups or more, and t-test was used for comparison of means between groups. $\mathrm{P}<0.05$ was considered statistically significant.

\section{The Results}

\subsection{Effects of Solanine on ATP in ACHN Cells}

The results showed that Solanine could reduce ATP production of ACHN cells in a concentration-dependent manner, and the difference between the experimental groups and the control group was statistically significant $(P<0.05)$, as shown in Table 1. 
Table 1. ATP production in ACHN cells treated with solanine at different concentrations for 48 hours $(\mathrm{n}=3, \bar{x} \pm s)$.

\begin{tabular}{cc}
\hline concentration $(\mu \mathrm{g} / \mathrm{mL})$ & ATP $(\mu \mathrm{mol} / \mathrm{mg})$ \\
\hline 0 & $35.45 \pm 0.32$ \\
0.5 & $31.11 \pm 0.32$ \\
2 & $19.55 \pm 2.98$ \\
8 & $7.38 \pm 1.07$ \\
F value & 54.38 \\
P value & $<0.05$ \\
\hline
\end{tabular}

\subsection{Expression Changes of HIF-1 $\alpha$, PI3K, Akt, p-PI3K and p-Akt in ACHN Cells Treated with Solanine}

Western blot results showed that after Solanine treatment, the relative expression of HIF- $1 \alpha, \mathrm{p}$-PI3K and p-Akt in Solanine groups decreased with the increase of drug concentration compared with the control group $(\mathrm{P}<0.05)$. The relative expression of $\mathrm{PI} 3 \mathrm{~K}$ and AKT had no significant change $(\mathrm{P}>0.05)$, as shown in Table 2.

\section{Discussion}

Solanine is an alkaloid extracted mainly from the whole grass or the immature fruit of the plant nightshade. Modern pharmacology confirms that Solanine is the main component of the plant Solanine. Recent studies have found that Solanine can inhibit the growth of cervical cancer, liver cancer, pancreatic cancer, breast cancer, lung cancer, prostate cancer, brain glioma and other tumors by inhibiting cell proliferation, inducing apoptosis, blocking cell cycle, inducing autophagy, inhibiting epithelial-mesenchymal transformation, inhibiting tumor angiogenesis and other aspects [10] [11] [12] [13]. However, the research on the anti-tumor activity of Solanine is still in the primary stage, and the anti-tumor activity of Solanine, especially the mechanism of action on renal cancer, remains to be further studied.

Metabolism, including substance metabolism and energy metabolism, is the basic characteristic of life activities. Glucose metabolism is the main energy source of cells, which mainly includes glycolysis and oxidative phosphorylation. Warburg et al. found that even under the condition of sufficient oxygen, although mitochondrial oxidative phosphorylation can produce more ATP, tumor cells still prefer to adopt glycolysis for glucose metabolism. This metabolic mode is called aerobic glycolysis, also known as Warburg effect, which is a major feature of tumor cells that is different from normal cells. However, HIF-1 $\alpha$ is involved in the glucose metabolism of tumor cells. The metabolic capacity of tumor cells is higher than that of surrounding normal tissues. The metabolic characteristic of tumor cells is that it provides a large amount of energy for itself through glucose glycolysis. In this pathway, HIF-1 $\alpha$ is mainly involved in regulating 
Table 2. Expression of HIF-1 $\alpha$, p-Akt, Akt, p-PI3K and PI3K proteins in ACHN cells treated with solanine at different concentrations $(\mathrm{n}=3, \bar{x} \pm s)$.

\begin{tabular}{cccccc}
\hline Concentration $(\mu \mathrm{g} / \mathrm{mL})$ & HIF-1 $\alpha$ & p-Akt & Akt & p-PI3K & PI3K \\
\hline 8 & $0.26 \pm 0.05$ & $0.24 \pm 0.02$ & $0.52 \pm 0.02$ & $0.21 \pm 0.12$ & $0.55 \pm 0.03$ \\
2 & $0.37 \pm 0.06$ & $0.28 \pm 0.01$ & $0.54 \pm 0.01$ & $0.25 \pm 0.01$ & $0.57 \pm 0.02$ \\
0.5 & $0.44 \pm 0.05$ & $0.31 \pm 0.01$ & $0.54 \pm 0.01$ & $0.28 \pm 0.02$ & $0.59 \pm 0.01$ \\
0 & $0.46 \pm 0.03$ & $0.37 \pm 0.01$ & $0.54 \pm 0.01$ & $0.36 \pm 0.03$ & $0.60 \pm 0.01$ \\
F value & 27.55 & 34.68 & 1.15 & 30.48 & 2.51 \\
P value & $<0.05$ & $<0.05$ & $>0.05$ & $<0.05$ & $>0.05$ \\
\hline
\end{tabular}

the expression of glucose transporter and hexokinase [14] [15]. High expression of HIF- $1 \alpha$ in tumor cells can up-regulate the expression of $1 / 3$ of glucose transporter and increase glucose uptake. Meanwhile, HIF-1 $\alpha$ can up-regulate the expression of most enzymes in the process of glycolysis and activate multiple steps of glycolysis [16]. The results of this study showed that Solanine can inhibit the proliferation of human renal carcinoma ACHN cells in vitro, reduce the expression of HIF- $1 \alpha$ protein, and reduce the generation of ATP, suggesting that Solanine can reduce the glycolysis of tumor cells by inhibiting the expression of HIF- $1 \alpha$ protein.

Phosphatidlinositol 3-kinase (PI3K)/serine threonine kinase (AKT) signal transduction pathway is involved in many important biological processes such as cell growth and apoptosis. PI3K/Akt signaling pathway is an important pathway in the downstream signal transduction pathway of Ras [17]. The activation of this pathway plays an important role in the inhibition of apoptosis of tumor cells and is closely related to the occurrence and development of a variety of tumors. Studies have shown that HIF-1 $\alpha$ synthesis is involved in the activation of this signal transduction pathway [18]. This study confirmed that Solanine had no effect on the protein expression of PI3K and Akt, but reduced the expression of p-PI3K and p-Akt. It is suggested that Solanine can down-regulate the PI3K/Akt pathway by inhibiting the phosphorylation of PI3K/p-PI3K and Akt/p-Akt.

Therefore, the anti-tumor target of Solanine is to inhibit the phosphorylation process of PI3K and Akt in the PI3K/Akt/mTOR/HIF- $1 \alpha$ signaling pathway, reduce the expression of p-PI3K and p-Akt, down-regulate the level of HIF- $1 \alpha$, inhibit the energy metabolism process of tumor cells and reduce the generation of ATP. Thus, the metabolic process of malignant tumors can be destroyed and the effect of inhibiting tumor growth can be achieved finally. However, the interaction between PI3K/Akt signaling pathway and other pathways in ACHN cells under the action of Solanine needs to be further studied and verified.

\section{Conflicts of Interest}

The authors declare no conflicts of interest regarding the publication of this paper. 


\section{References}

[1] Khalil Ibrahim, A. (2013) Trends of Adult Primary Malignant Renal Tumors over 6 Years. Pakistan Journal of Medical Sciences, 29, 1385-1388. https://doi.org/10.12669/pjms.296.3736

[2] National Cancer Institute (2016) Cancer of the Kidney and Renal Pelvis Seer Stat Fact Sheets. https://seer.cancer.gov/statfacts/html/kidrp.html

[3] Jia, Y., Zuo, D., Li, Z., Liu, H., Dai, Z., Cai, J., et al. (2014) Astragaloside IV Inhibits Doxorubicin-Induced Cardiomyocyte Apoptosis Mediated by Mitochondrial Apoptptic Pathway via Activating the PI3K/Akt Pathway. Chemical and Pharmaceutical Bulletin, 62, 45-53. https://doi.org/10.1248/cpb.c13-00556

[4] Bodnar, L., Stec, R., Cierniak, S., Synowiec, A., Wcisło, G., Jesiotr, M., et al. (2015) Clinical Usefulness of PI3K/Akt/mTOR Genotyping in Companion with Other Clinical Variables in Metastatic Renal Cell Carcinoma Patients Treated with Everolimus in the Second and Subsequent Lines. Annals of Oncology, 26, 1385-1389. https://doi.org/10.1093/annonc/mdv166

[5] Jain, R., Sharma, A., Gupta, S., Sarethy, I.P. and Gabrani, R. (2011) Solanum Nigrum: Current Perspectives on Therapeutic Properties. Alternative Medicine Review, 16, 78-85.

[6] Al Sinani, S.S., Eltayeb, E.A., Coomber, B.L. and Adham, S.A. (2016) Solamargine Triggers Cellular Necrosis Selectively in Different Types of Human Melanoma Cancer Cells through Extrinsic Lysosomal Mitochondrial Death Pathway. Cancer Cell International, 16, Article No. 11. https://doi.org/10.1186/s12935-016-0287-4

[7] Pan, B., Zhong, W., Deng, Z., Lai, C., Chu, J., Jiao, G., et al. (2016) Inhibition of Prostate Cancer Growth by Solanine Requires the Suppression of Cell Cycle Proteins and the Activation of ROS /P38 Signaling Pathway. Cancer Medicine, 5, 3214-3222. https://doi.org/10.1002/cam4.916

[8] Zhang, F., Yang, R., Zhang, G., Cheng, R., Bai, Y., Zhao, H., et al. (2016) Anticancer Function of $\alpha$-Solanine in Lung Adenocarcinoma Cells by Inducing Micro RNA-138 Expression. Tumor Biology, 37, 6437-6346. https://doi.org/10.1007/s13277-015-4528-2

[9] Wen, Z., Huang, C., Xu, Y., Xiao, Y., Tang, L., Dai, J., et al. (2016) $\alpha$-Solanine Inhibits Vascular Endothelial Growth Factor Expression by Down-Regulating the ERK1/2-HIF-1 $\alpha$ and STAT3 Signaling Pathways. European Journal of Pharmacology, 771, 93-98. https://doi.org/10.1016/j.ejphar.2015.12.020

[10] Mohsenikia, M., Farhangi, B., Alizadeh, A.M., Khodayari, H., Khodayari, S., Khori, V., et al. (2016) Therapeutic Effects of Dendrosomal Solanine on a Metastatic Breast Tumor. Life Sciences, 148, 260-267. https://doi.org/10.1016/j.lfs.2016.02.008

[11] Deng, J. (2017) How to Unleash Mitochondrial Apoptotic Blockades to Kill Cancers? Acta Pharmaceutica Sinica B, 7, 18-26. https://doi.org/10.1016/j.apsb.2016.08.005

[12] Ying, Y. and Padanilam, B.J. (2016) Regulation of Necrotic Cell Death: p53, PARP1 and Cyclophilin D-Overlapping Pathways of Regulated Necrosis? Cellular and Molecular Life Sciences, 73, 2309-2324. https://doi.org/10.1007/s00018-016-2202-5

[13] Lv, C., Kong, H., Dong, G., Liu, L., Tong, K., Sun, H., et al. (2014) Antitumor Efficacy of $\alpha$-Solanine against Pancreatic Cancer in Vitro and in Vivo. PLoS ONE, 9 , e87868. https://doi.org/10.1371/journal.pone.0087868

[14] Gosalvez, M. (2013) Metabolic Control of Respiration and Glycolysis of Tumoral Cells. Advances in Biological Chemistry, 3, 86-89. 
https://doi.org/10.4236/abc.2013.31011

[15] Mohsenikia, M., Alizadeh, A.M., Khodayari, S., Khodayari, H., Amin Kouhpayeh, S., Karimi, A., et al. (2013) The Protective and Therapeutic Effects of Alpha-Solanine on Mice Breast Cancer. European Journal of Pharmacology, 718, 1-9. https://doi.org/10.1016/j.ejphar.2013.09.015

[16] Karar, J. and Maity, A. (2011) PI3K/Akt/mTOR Pathway in Angiogenesis. Frontiers in Molecular Neuroscience, 4, Article No. 51. https://doi.org/10.3389/fnmol.2011.00051

[17] Mazzoletti, M. and Broggini, M. (2010) PI3K/Akt /m-TOR Inhibitors in Ovarian Cancer. Current Medicinal Chemistry, 17, 4433-4447.

https://doi.org/10.2174/092986710794182999

[18] Saini, K.S., Loi, S., de Azambuja, E., Metzger-Filho, O., Lamba Saini, M., Ignatiadis, M., et al. (2013) Targeting the PI3K/AKT/mTOR and Raf /MEK/ERK Pathways in the Treatment of Breast Cancer. Cancer Treatment Reviews, 39, 935-946.

https://doi.org/10.1016/j.ctrv.2013.03.009 